\title{
Current management and outcome of pregnancies in women with adrenal insufficiency: experience from a multi-center survey
}

Christina Bothou ${ }^{1}$, Gurpreet Anand ${ }^{1}$, Dingfeng $\mathrm{Li}^{2}$, Tina Kienitz ${ }^{3}$, Khyatisha Seejore ${ }^{4}$, Chiara Simeoli ${ }^{5}$, Andreas Ebbehoj ${ }^{6}$, Emma G. Ward ${ }^{4}$, Rosa Maria Paragliola ${ }^{7}$, Rosario Ferrigno ${ }^{5}$, Klaus Badenhoop $^{8}$, Sophie Bensing ${ }^{9}$, Marianne Oksnes $^{3,}{ }^{10}$, Daniela Esposito ${ }^{11,12}$ Ragnhildur Bergthorsdottir ${ }^{11,12}$, William Drake ${ }^{13}$, Jeanette Wahlberg ${ }^{14}$, Nicole Reisch ${ }^{15}$, Stefanie Hahner ${ }^{16}$, Simon Pearce ${ }^{17}$, Peter Trainer ${ }^{18}$, Gwendolin Etzrodt-Walter ${ }^{19}$, Sébastien P. Thalmann ${ }^{20}$, Åse B. Sævik $^{10}$, Eystein Husebye ${ }^{10}$, Andrea M. Isidori ${ }^{21}$, Henrik Falhammar ${ }^{9}$, Gesine Meyer ${ }^{8}$, Salvatore M. Corsello ${ }^{7}$, Rosario Pivonello ${ }^{5}$, Robert Murray ${ }^{4}$, Irina Bancos ${ }^{2}$, Marcus Quinkler ${ }^{3}$, Felix Beuschlein ${ }^{1,15}$

${ }^{1}$ Klinik für Endokrinologie, Diabetologie und Klinische Ernährung, Universitätsspital Zürich, Zürich, Switzerland

${ }^{2}$ Division of Endocrinology, Diabetes, Metabolism and Nutrition, Mayo Clinic, Rochester, Minnesota, USA

${ }^{3}$ Endocrinology in Charlottenburg, Berlin, Germany

${ }^{4}$ Department of Endocrinology, Leeds Teaching Hospitals NHS Trust, St James's University Hospital, Leeds, U.K

${ }^{5}$ Dipartimento di Medicina Clinica e Chirurgia, Sezione di Endocrinologia, Università Federico II di Napoli, Naples, Italy

${ }^{6}$ Department of Clinical Medicine, Department of Endocrinology and Diabetes, Aarhus University, Aarhus, Denmark

${ }^{7}$ Unit of Endocrinology, Università Cattolica del Sacro Cuore - Fondazione Policlinico Universitario Agostino Gemelli IRCCS, Rome, Italy

${ }^{8}$ Department of Internal Medicine I, Division of Endocrinology, Diabetes and Metabolism, University Hospital, Frankfurt, Germany

${ }^{9}$ Department of Molecular Medicine and Surgery, Karolinska Institutet and Department of Endocrinology, Inflammation and Infection Theme, Karolinska University Hospital, Stockholm, Sweden

${ }^{10}$ Department of Clinical Science and K.G. Jebsen Center for Autoimmune Disorders, University of Bergen, Jonas Liesvei 65, N-5021 Bergen, Norway

${ }^{11}$ Department of Internal Medicine and Clinical Nutrition, Institute of Medicine, Sahlgrenska Academy, University of Gothenburg, 40530 Gothenburg, Sweden ${ }^{12}$ Department of Endocrinology, Sahlgrenska, University Hospital, 41345 Gothenburg, Sweden

(C) Endocrine Society 2020. All rights reserved. For permissions, please e-mail: journals.permissions@oup.com. jc.2020-00555. See endocrine.org/publications for Accepted Manuscript disclaimer and additional information. 
${ }^{13}$ Department of Endocrinology, St Bartholomew's Hospital, London EC1A 7BE, UK

${ }^{14}$ Department of Endocrinology, and Department of Health, Medicine and Caring Sciences, Linköping University, Linköping, Sweden

${ }^{15}$ Department of Endocrinology, Medizinische Klinik und Poliklinik IV, Klinikum der Universität München, Munich, Germany

${ }^{16}$ Department of Internal Medicine I, Endocrinology and Diabetes Unit, University Hospital of Würzburg, University of Würzburg, Germany

${ }^{17}$ Translational and Clinical Research Institute, Newcastle University, Newcastle upon Tyne, U.K.

${ }^{18}$ The Christie NHS Foundation, MAHSC, Wilmslow Road, Manchester M20 4BX, U.K

${ }^{19}$ Praxis Dr. Etzrodt-Walter Endokrinologiezentrum Ulm, Ulm, Germany

${ }^{20}$ Ärztezentrum Sihlcity, Zurich, Switzerland

${ }^{21}$ Department of Experimental Medicine, Sapienza University of Rome, Rome, Italy

Abbreviated title: Pregnancies in adrenal insufficiency

Key terms: Addison disease, congenital adrenal hyperplasia, pregnancy, mineralocorticoid, glucocorticoid, adrenal crisis, miscarriage

Abbreviations: Al, adrenal insufficiency; AD, Addison disease; HPA, Hypothalamic- Pituitary- Adrenal; ACTH, Adrenocorticotropic hormone; BMI, Body Mass Index; HC, hydrocortisone; MCU, mineralocorticoid unit; $\mathrm{CAH}$, congenital adrenal hyperplasia; $\mathrm{CS}$, caesarean section 
Corresponding author and person to whom reprint request should be addressed:

Prof. Felix Beuschlein, M.D.

Klinik für Endokrinologie, Diabetologie und Klinische Ernährung

Universitätsspital Zürich

Raemistrasse 100, CH-8091 Zürich, Switzerland

Phone: +41 4425536 25, Fax: +414425533 30

E-mail: felix.beuschlein@usz.ch

Disclosure statement: FB serves as an associate editor of the JCE\&M. IB reports advisory board participation with Corcept, HRA Pharma, and ClinCor outside the submitted work. This research was supported by the James A. Ruppe Career Development Award in Endocrinology (IB) and the Catalyst Award for Advancing in Academics from Mayo Clinic (IB). This research was partly supported by the National Institute of Diabetes and Digestive and Kidney Diseases (NIDDK) of the National Institutes of Health (NIH) USA under award K23DK121888 (to I.B). The views expressed are those of the author(s) and not necessarily those of the National Institutes of Health USA. All other authors have nothing to disclose. 


\section{Abstract}

Context: Appropriate management of adrenal insufficiency (Al) in pregnancy can be challenging due to the rarity of the disease and lack of evidence-based recommendations to guide glucocorticoidand mineralocorticoid dosage adjustment.

Objective: Multi-center survey on current clinical approaches in managing Al during pregnancy.

Design: Retrospective anonymized data collection from 19 international centers from 2013-2019.

Setting and Patients: 128 pregnancies in 113 women with different causes of Al: Addison disease (44\%), secondary Al (25\%), congenital adrenal hyperplasia (25\%) and acquired Al due to bilateral adrenalectomy (6\%).

Results: Hydrocortisone (HC) was the most commonly used glucocorticoid in $82.9 \%(97 / 117)$ of pregnancies. Glucocorticoid dosage was increased at any time during pregnancy in $73 / 128(57 \%)$ of cases. In these cases, difference of the daily dose of $\mathrm{HC}$ equivalent between baseline and the third trimester was 8.6 \pm 5.4 [range: 1,30 ] $\mathrm{mg}$. Fludrocortisone dosage was increased in fewer cases $(7 / 54$ during the first trimester, 9/64 during the second trimester and 9/62 cases during the last trimester). Overall, an adrenal crisis was reported in 9/128 (7\%) pregnancies. Caesarian section was the most frequent mode of delivery at 58\% (69/118). Fetal complications were reported in 3/120 (2.5\%) and minor maternal complications in 15/120 (12.5\%) pregnancies without fatal outcomes.

Conclusions: This survey confirms good maternal and fetal outcome in women with Al managed in specialized endocrine centers. An emphasis on careful endocrine follow up and repeated patient education is likely to have reduced the risk of adrenal crisis and resulted in positive outcomes.

Précis: Good maternal and fetal outcome can be expected in appropriately managed Al. 


\section{Introduction}

Adrenal insufficiency (AI) is a potentially life-threatening condition that can be caused by destruction of adrenocortical cells, by inborn alterations of steroidogenesis or by impairment of pituitary or hypothalamic stimulation of the adrenal cortex (1). Al is associated with an increased mortality risk and a reduced quality of life, as well as reduced ability to work (2). As Al predominantly affects women in their reproductive age, course and outcome of pregnancy may be affected. While the exact prevalence of $\mathrm{Al}$ in pregnancy is unknown, a recent population-based study from the United States reported an increase in prevalence of Addison disease (AD) from 5.6 per 100,000 in 2003 to 9.6 per 100,000 in 2011 in a cohort with 7.7 million births (3).

Prior to the introduction of glucocorticoid replacement therapy, AD was associated with a high maternal mortality (4). However, modern glucocorticoid replacement therapy and improved obstetric care have both contributed immensely in reducing maternal as well as fetal morbidity and mortality. In patients with primary Al, replacement of both glucocorticoid and mineralocorticoid are usually necessary, while in secondary or tertiary Al, only glucocorticoid substitution is required. However, it might be necessary to replace other deficient hormones in both primary Al, if it occurs as a part of polyglandular autoimmune syndrome (5) as well as in secondary $\mathrm{Al}$, if other pituitary axes are affected (6). Particularly, women with secondary Al may need assisted reproduction techniques for conception (7). Accordingly, a population-based study on patients with primary Al from Sweden has indicated a persistently reduced parity, increased rate of preterm birth and low birth weight (8). While these studies have offered many important insights on a population basis, they fail to provide information on therapeutic strategies currently applied in this patient group. 
Pregnancy can be considered as a state of hypercortisolism due to the upregulation of the whole hypothalamic-pituitary-adrenal (HPA) axis. Furthermore, bound cortisol levels are increased due to increased corticosteroid binding globulin under the high estrogen-state of pregnancy (9). Several biochemical parameters such as morning cortisol, adrenocorticotropic hormone (ACTH), plasma sodium and renin change physiologically in pregnancy and are therefore not reliable in dosage titration of replacement therapies. Diagnosing new onset Al in pregnant women is further complicated as many indicators suggestive of Al could be potentially mistaken as symptoms of pregnancy. Nevertheless, clinical information such as general well-being, appropriate weight gain during the course of pregnancy, blood pressure and potassium levels may help in adjusting glucocorticoid- and mineralocorticoid dosage. Ongoing follow-up during pregnancy, ideally from an endocrinologist, can be expected to facilitate the appropriate management of Al to ensure selfadjustment of glucocorticoid dosage in response to potential stress events (10). Furthermore, improved obstetric care and increased awareness among physicians regarding the importance of individualized dosage adjustment of glucocorticoid and or mineralocorticoid replacement have likely contributed in improving outcomes in this rare disease. The clinical guidelines from the Endocrine Society suggest an empirical increase in hydrocortisone dosage by $20-40 \%$ in the last trimester $(11,12)$. However, this suggestion is based on low level of evidence. Therefore, the aim of our multicenter retrospective survey was to analyze the current management approaches of dosage adjustment in pregnant women with $\mathrm{Al}$ in specialized centers and to assess the maternal and fetal outcome. 


\section{Material and methods}

\section{Patients and pregnancies}

We collected data on 128 pregnancies in 113 women with Al from 19 centers with varying number of pregnancies per center (range 1-28 per center). Data collection was restricted to pregnancies between 2013 and 2019. Minimal clinical annotations for inclusion in the study were patient's age, etiology of $\mathrm{Al}$, maternal and fetal outcome, presence of adrenal crisis during pregnancy and mode of delivery. Pre-defined data points were collected by each center for each individual patient. Upon anonymization, data were transferred for central analysis. The central ethical Committee of the University of Zurich approved this study and provided a waiver of consent to collect retrospective data from different centers in an anonymized form. Where required, centers obtained additional local ethical approval for data collection.

We assessed clinical and biochemical parameters before pregnancy and during all three trimesters [first $\left(1^{\text {st }}\right)$ trimester weeks $1-13$, second $\left(2^{\text {nd }}\right)$ trimester weeks $14-27$ and third $\left(3^{\text {rd }}\right)$ trimester weeks 28-40 of pregnancy]. Main clinical parameters included weight, height, body mass index (BMI), blood pressure and main biochemical parameters were serum sodium and potassium. Maternal outcome was classified as good, with complications or fatal. Likewise, fetal outcome was defined as good, with complications or fatal.

We converted glucocorticoid medication to equivalent dose of immediate release $\mathrm{HC}$ dosage, as follows: $1 \mathrm{mg}$ dual - release $\mathrm{HC}$ as $1 \mathrm{mg} \mathrm{HC}$ equivalent, $1 \mathrm{mg}$ prednisone and prednisolone as $4 \mathrm{mg}$ of $\mathrm{HC}$, $1 \mathrm{mg}$ cortisone acetate as $0.8 \mathrm{mg} \mathrm{HC}$, and $1 \mathrm{mg}$ dexamethasone as $25 \mathrm{mg}$ (13). The mineralocorticoid potency of $100 \mu \mathrm{g}$ fludrocortisone was defined as 1 mineralocorticoid unit (MCU). For the glucocorticoids, we calculated $1 \mathrm{mg}$ immediate and dual release $\mathrm{HC}$ as a mineralocorticoid 
potency of $0.054 \mathrm{MCU}, 1 \mathrm{mg}$ prednisone or prednisolone as $0.013 \mathrm{MCU}, 1 \mathrm{mg}$ cortisone acetate as $0.0432 \mathrm{MCU}$, respectively, while dexamethasone was regarded as $0 \mathrm{MCU}$ (14).

\section{Statistical analysis}

Each individual pregnancy was considered as independent cases including the ones occurring in the same patient. The retrospective, case- based form of the study resulted in missing data in different variables that could be explained either by lack of documentation or incomplete follow-up of the patient by the participating centers. Further missing data across all pregnancies are explained by miscarriages or ongoing pregnancies. Data were gathered from participating centers in an anonymized form. Statistical analysis was performed using IBM SPSS Statistics for Windows (Released 2017, Version 25.0., IBM Corp, Armonk, NY). Graphs were generated using GraphPad Prism 5 (GraphPad Software, La Jolla, CA, United States). Variables were assessed for normality by evaluation of histograms and by Kolmogorov-Smirnov test. Differences between groups were assessed using Fisher's exact test for categorical variables, Mann-Whitney U-test for quantitative non-normally distributed variables and Student's t-test for normally distributed variables. Overall, comparisons of continuous variables between groups were carried out by using ANOVA or the Kruskal-Wallis test. Correlations were assessed by Pearson's or Spearman's correlation coefficient (r). For paired data, the Wilcoxon's test was used. A probability value of $p<0.05$ was considered statistically significant for all tests. If not stated otherwise, $p<0.05$ were denoted with one $\operatorname{star}\left({ }^{*}\right), p<$ 0.01 with two stars $(* *)$, and $p<0.001$ with three stars $(* * *)$, respectively. 


\section{Results}

\section{Description of patients with Al}

The cause of $A l$ was $A D$ in the context of 56 pregnancies (44\%), secondary $A l$ in 32 pregnancies (25\%), and congenital adrenal hyperplasia (CAH) in 32 pregnancies (25\%). In eight pregnancies (6\%), the cause was bilateral adrenalectomy performed for treatment of bilateral pheochromocytoma or therapy resistant ACTH dependent Cushing syndrome.

The mean age of women at the time of Al diagnosis differed significantly among the subgroups with 26 years ([range 14-35], $n=48$ ) for primary Al, 26 years ([range 8-44], $n=31$ ) for secondary Al, 9 years ([range 0-38], $n=29)$ for $\mathrm{CAH}$ and 30 years ([range 23-37], $n=6)$ for other causes of $\mathrm{Al}(\mathrm{p}<0.001$, Table 1). In contrast, the mean age at the time of pregnancy was similar among different groups with $33 \pm 4.5$ years in women with $A D, 32 \pm 5.5$ in women with secondary $\mathrm{Al}, 32 \pm 6.1$ in $\mathrm{CAH}$ and $35 \pm 3.8$ in $\mathrm{Al}$ due to other reasons $(p=0.470$, Table 1$)$. In most pregnancies $(125 / 128,98 \%)$, the diagnosis of Al had been established before pregnancy. In two cases, Al was diagnosed during the third trimester (in the $28^{\text {th }}$ and $34^{\text {th }}$ week of gestation).

Among women with secondary $\mathrm{Al}, 45 \%$ (14/31) had at least one additional hormonal deficiency. Thyroid dysfunction was the most commonly reported additional comorbidity with $46.8 \%(52 / 111)$ having hypothyroidism. Hypothyroidism coexisted in primary Al as primary hypothyroidism in $55 \%$ (26/47) and as secondary hypothyroidism in women with secondary Al in $55 \%(17 / 29)$ of cases. In contrast, fewer patients with $\mathrm{CAH}$ had hypothyroidism (21\%). Some women had other diseases of the thyroid, e.g., multinodular goiter $(n=1)$, thyroid nodules $(n=2)$, hyperthyroidism that was not otherwise specified $(n=1)$, Graves disease $(n=1)$ and papillary thyroid carcinoma $(n=2)$. 


\section{Reproductive history of patients with Al}

$28.3 \%(36 / 127)$ of the women had at least one miscarriage in the past medical history. The percentage of miscarriages was significantly higher among $\mathrm{CAH}$ patients $(43.8 \%, 14 / 32)$ compared with $\operatorname{AD}(27.3 \%, 15 / 55)$ and was considerably lower in patients with secondary $\mathrm{Al}(15.6 \%, 5 / 32)$ or due to other diseases $(25 \%, 2 / 8)$ (all $p<0.001)$. The exact week of miscarriage was recorded in 28 cases with $75 \%$ of miscarriages occurring in the first trimester and $25 \%$ in the second trimester. From 2013 onwards, three miscarriages were reported, two in the $9^{\text {th }}$ week and one in the $15^{\text {th }}$ week of gestation.

\section{Management of glucocorticoid and mineralocorticoid substitution therapy during pregnancy}

\section{Glucocorticoid substitution}

At baseline, immediate release HC was the most commonly used glucocorticoid $(67 / 100,67 \%)$ with considerably fewer patients treated with other single medication $(18 / 100,18 \%$ dual release HC; $8 / 100,8 \%$ prednisolone; $2 / 100,2 \%$ dexamethasone, $2 / 100,2 \%$ cortisone acetate) or combinatory therapies $(2 / 100,2 \%$ immediate release $\mathrm{HC}$ with dexamethasone and $1 / 100,1 \%$ immediate release $\mathrm{HC}$ with prednisolone). Treatment data at baseline were not available for 26 pregnancies while in further two cases, Al was first diagnosed during pregnancy. Of note, in one case, immediate release $\mathrm{HC}$ was given continuously through a subcutaneous pump throughout pregnancy (15).

During the $1^{\text {st }}$ trimester, in $80 / 117(68.4 \%)$ pregnancies the reported glucocorticoid was immediate release $\mathrm{HC}$, in $15 / 117(12.8 \%)$ dual release $\mathrm{HC}$, in $2 / 117$ (1.7\%) a combination of both, in $11 / 117$ (9.4\%) prednisolone, in $7 / 117(6.0 \%)$ cortisone acetate and in $2 / 117(1.7 \%)$ combination of 
prednisolone with HC. In contrast, no cases of dexamethasone treatment were reported. The split of the dosage for the immediate release HC formulation was twice per day in $28 / 80$ (35.0\%) cases and three times per day in $51 / 80$ (63.7\%) of the pregnancies and four times per day for one pregnancy $(1 / 80,1.3 \%)$. Of note, in two pregnancies with dual release $\mathrm{HC}(2 / 15,13.3 \%)$, the treatment scheme was $20 \mathrm{mg}$ in the morning supplemented with another $5 \mathrm{mg}$ in the afternoon.

Applied glucocorticoid during the further course of pregnancy remained comparable with those of the $1^{\text {st }}$ trimester (data not shown). Of note, dexamethasone was added as the only glucocorticoid in two patients with CAH during the $17^{\text {th }}$ and the $32^{\text {nd }}$ week of pregnancy, respectively.

Glucocorticoid dosage was not adapted uniformly in line with existing guidelines. Instead, data revealed individualized dosage adaptation during the different trimesters following no certain pattern but there were also cases where the dosage was not changed during the whole course of pregnancy (Figure 1). In none of the cases with a decrease of the dosage, the occurrence of an adrenal crisis was reported. During the last trimester, 5/109 patients (4.6\%) had a decrease in daily dosage by 5-10 mg of $\mathrm{HC}$ equivalent due to the development of hypertension. Among the different subgroups, those with AD tended to receive the highest substitution dosage (Table 2).

\section{Mineralocorticoid substitution}

Before pregnancy, $95 \%$ (37/39) of patients with AD, $42 \%$ (13/31) of patients with CAH and $80 \%(4 / 5)$ of patients with Al due to other diseases were receiving fludrocortisone treatment. As expected, none of the patients $(0 / 32)$ with secondary Al had mineralocorticoid substitution. During the whole course of pregnancy, fludrocortisone dosage was adapted in some cases but to a lesser extent in comparison to the $\mathrm{HC}$ adaptation (Figure 1). The reason for decrease in fludrocortisone dosage was 
not recorded; particularly no correlation with increased blood pressure or onset of preeclampsia was documented.

\section{Clinical course and adrenal crisis during pregnancy}

Blood pressure measurements as well as serum sodium and potassium remained in the normal range during the course of pregnancy in the majority of cases (Table 3 and Figure 2). Hypertensive values (defined as values above $140 / 90 \mathrm{mmHg}$ ) were reported in $6 / 94(6.4 \%)$ at baseline, in $2 / 102$ $(2 \%)$ in the $1^{\text {st }}$ trimester, in $2 / 102(2 \%)$ during the $2^{\text {nd }}$ trimester and in $7 / 100(7 \%)$ in the $3^{\text {rd }}$ trimester. No relevant differences were noted among the subgroups. Similarly, no significant differences in systolic and diastolic blood pressure were evident during pregnancy in comparison to baseline levels (Figure 2). In contrast, sodium concentrations decreased significantly compared to baseline $(139.0 \pm 3.1$ [range: $125-145$ ] $\mathrm{mmol} / \mathrm{l})$ in the $1^{\text {st }}$ trimester $(136.3 \pm 2.7$ [range: $130-144] \mathrm{mmol} / \mathrm{l}$, $\mathrm{p}<0.001), 2^{\text {nd }}(136.7 \pm 2.9$ [range: $132-145$ ] $\mathrm{mmol} / \mathrm{l}, \mathrm{p}<0.001)$ and $3^{\text {rd }}$ trimester $(137.7 \pm 2.8$ [range: $129-$ 145] $\mathrm{mmol} / \mathrm{l}, \mathrm{p}=0.0036$ ). Low serum sodium concentrations ( $<135 \mathrm{mmol} / \mathrm{L}$ ) were reported in $3 / 79$ (3.8\%) at baseline, in $21 / 94(22.3 \%)$ in the $1^{\text {st }}$ trimester, in $22 / 91(24.2 \%)$ in the $2^{\text {nd }}$ trimester and in $9 / 82(11.0 \%)$ in the $3^{\text {rd }}$ trimester.

With regard to serum potassium levels only minor changes were observed between baseline (4.2 \pm 0.4 [range: $3.0-5.5$ ] $\mathrm{mmol} / \mathrm{l})$ and $2^{\text {nd }}$ trimester $(4.0 \pm 0.4$ [range: $3.0-5.0$ ] $\mathrm{mmol} / \mathrm{l}, \mathrm{p}=0.0234$; Figure 2). Low serum potassium levels $(<3.5 \mathrm{mmol} / \mathrm{L})$ were reported in $2 / 79(2.5 \%)$ at baseline and in $3 / 94(3.2 \%), 5 / 91(5.5 \%)$ and in $5 / 82(6.1 \%)$ during $1^{\text {st }}, 2^{\text {nd }}$ and $3^{\text {rd }}$ trimester, respectively. 
No case of hypernatremia ( $>145 \mathrm{mmol} / \mathrm{L}$ ) or hyperkalemia $(>5.5 \mathrm{mmol} / \mathrm{L})$ was reported at any time point. When taking into consideration the mineralocorticoid substitution and serum electrolytes in the $3^{\text {rd }}$ trimester of pregnancy, a negative correlation between the total mineralocorticoid potency and serum sodium $(R=-0.217, p=0.047)$ and a positive correlation for serum potassium were observed ( $\mathrm{R}=0.281, \mathrm{p}=0.011$ Figure 3 ). In contrast, no significant correlation was found at any other time point before or during pregnancy (Figure 3).

In 9/128 (7\%) of pregnancies, an adrenal crisis was reported without any relationship to the etiology of Al (Table 4). In one case, adrenal crisis was precipitated by an influenza A infection, which was successfully managed. One patient experienced four recurring episodes of adrenal crisis due to hyperemesis gravidarum during the first trimester. In one case, the trigger was gastroenteritis during the $1^{\text {st }}$ trimester. One patient was diagnosed with new $\mathrm{Al}$ when she presented with adrenal crisis in the $3^{\text {rd }}$ trimester. In the other five cases, no further data regarding onset and cause of adrenal crisis was available.

\section{Delivery management and outcome}

Overall, 25/117 (21.4\%) deliveries were reported as preterm without significant differences between the subgroups. Among those preterm births in patients with $\mathrm{CAH} 1 / 10$ (10\%) was defined as extremely preterm $\left(25^{\text {th }}\right.$ week) in the context of chorioamnionitis. A further early preterm birth $\left(28^{\text {th }}\right.$ week) in a patient with $A D$ was reported but no further details of the etiology were available. The remaining preterm births were moderate to late preterm $\left(28^{\text {th }}\right.$ to $32^{\text {nd }}$ week $)$. 
Information regarding administration of stress dosage of glucocorticoid during delivery was available in $90 / 128$ cases $(70.3 \%)$, of whom $83 / 90$ cases $(92.2 \%)$ glucocorticoids were administered intravenously. In the seven cases where no stress dosage was provided, no adverse events were reported. In 54/90 cases, the exact dosage of substitution medication was available. The majority of these cases $(36 / 54,66.7 \%)$ received $100 \mathrm{mg}$ hydrocortisone, but overall a wide range of dosages of HC supplementation were used ranging from 50 to $300 \mathrm{mg}$.

Mode of delivery was CS in 69/118 (58\%) of the cases. However, only a few cases had emergency CS $(n=4)$ due to preeclampsia. Vaginal delivery was slightly more common in patients with AD $(52 \%$, $26 / 50)$. CS was more common in patients with secondary $\operatorname{Al}(20 / 29,69 \%)$, patients with CAH $(20 / 31$, $65 \%)$, and patients with other types of $\mathrm{Al}(5 / 8,63 \%)$. The exact reason for CS was not documented in these cases.

In $15 / 120(12.5 \%)$ cases, maternal complications were reported: anemia $(n=2)$, severe postpartum hemorrhage $(n=4)$, mild to severe pre-eclampsia $(n=7)$ and chorioamnionitis $(n=1)$. However, no adverse fetal outcomes were reported in these cases. In three cases, miscarriage was documented, two in $9^{\text {th }}$ week and one in $15^{\text {th }}$ week of pregnancy. Two pregnancies were ongoing at the time of study completion. In three cases, fetal complications occurred with two premature babies requiring intensive care and one having macrosomia and shoulder dystocia in a woman with type 1 diabetes. No maternal or fetal fatalities occurred. 


\section{Discussion}

To our knowledge, this is the first retrospective multicenter survey with a detailed analysis of course, management and outcome of a large number of pregnancies in women with Al of different etiologies. As these women had regular follow-up at specialized endocrine units during the course of their pregnancy, it was possible to collect and analyze information that sheds light on the current treatment and management of this rare clinical condition and to provide insights on the outcome of affected mothers and their offspring.

Miscarriages were relatively prevalent in the past medical history of included women, being highest among those with $\mathrm{CAH}$. A high rate of miscarriages among patients with CAH has previously been described in a German cohort that included 39 patients with either classical or non-classical form of CAH (16) and were attributed to a combination of androgen excess and cortisol insufficiency. A Swedish study reported increased rates of therapeutic abortions among 62 patients with $\mathrm{CAH}$, while the rate of spontaneous abortions were not higher in comparison to a control population (17).

Interestingly, in the current dataset, women with secondary Al had the lowest rate of spontaneous abortion, but this could be explained by the usage of assisted reproduction methods for conception often guided by frequent follow-up during pregnancy. Overall, the reasons of reduced fertility in women with secondary $\mathrm{Al}$ are believed to be caused by additional hormonal deficiencies such as hypothyroidism and or secondary hypogonadism (7). Almost one out of three patients with AD reported a miscarriage in the past medical history but the reasons could not be determined in the context of the present study. However, overall, this rate is within the range (15-30\%) of the normal population $(18,19)$. 
In the past, many cases of primary Al were reported to result in maternal and fetal death but recent reports correlate adverse events mostly with poor compliance (20). In the present study, the rate of miscarriages among patients with $\mathrm{AD}, \mathrm{CAH}$ and $\mathrm{Al}$ due to other etiologies was comparable with the reported rate in a similar study of patients with primary Al in the German population (16). Of note, in that study, all miscarriages were reported among patients that suffered from primary Al in the context of autoimmune polyendocrine syndrome type 2 . This information was not available in our dataset and we could not access the incidence of miscarriages in parallel with other manifestations of the syndrome, for example in combination with hypothyroidism.

The objective of the follow-up of a woman with Al during pregnancy is to keep the replacement therapy at levels that avoid effects of over-treatment (e.g. gestational diabetes, excessive weight gain, arterial hypertension) and of under-treatment (adrenal crisis, electrolyte imbalance). In keeping with the general recommendation from the Endocrine Society (11), glucocorticoids were in most instances increased during the course of pregnancy in a range between 5 and $25 \mathrm{mg}$ hydrocortisone equivalents. However, adjustment of glucocorticoid dosage varied significantly among patients and centers emphasizing that current practice is a rather individualized approach.

Likewise, fludrocortisone dosage was adjusted in almost a quarter of patients, without a clear relationship with potassium concentrations or blood pressure measurements. Electrolyte balance during pregnancy is affected by the mineralocorticoid antagonistic action of progesterone $(21,22)$. To counterbalance the effects of increased progesterone levels during pregnancy, higher doses of a mineralocorticoid receptor agonist are required $(22,23)$. Proper adjustment of mineralocorticoid dosage is accomplished by evaluating blood pressure and assessment of blood electrolytes, as active renin cannot be used as a reliable indicator for the treatment during pregnancy (14). Despite the 
observed tendency of increasing mineralocorticoid potency during the course of pregnancy in the majority of cases, serum sodium showed an initial decrease in the first trimester. Afterwards, there was no further change in serum sodium and serum potassium remained stable during the course of pregnancy. Our findings support an earlier report that pregnant women with primary Al have an increasing requirement for fludrocortisone substitution as pregnancy advances to maintain blood pressure and serum potassium in the normal range (24). However, also during normal pregnancy despite increased sodium retention the increase in plasma volume results in mildly reduced serum sodium concentrations. Accordingly, reference intervals of a pregnant women are approximately 2$5 \mathrm{mmol} / \mathrm{L}$ lower those outside of pregnancy (25). Therefore, the observed reduced mean serum sodium levels during pregnancy could be explained by a combination of physiological effects of pregnancy and modulation by mineralocorticoid action implemented by the substitution treatment. It is interesting to note, that the current data for the 3rd trimester indicated a negative correlation between the total mineralocorticoid potency and serum sodium while it was positive for serum potassium levels. This pattern provides indirect evidence that changes in electrolytes had been the trigger for an increase in substitution therapy while it was less likely to be explained by steroid overdosage.

The reported rate of adrenal crisis of around $7 \%$ in the current study is within an expected range considering the high incidence of adrenal crisis even among educated populations based on recent studies $(10,26)$. To avoid development of an adrenal crisis during delivery, the endocrinologist should provide the obstetric team with a written therapeutic plan regarding intravenous glucocorticoid coverage. This should be started before the active phase of labor with a recommended initial bolus of $100 \mathrm{mg}$ hydrocortisone followed by continuous infusion or bolus dosages every 6 hours (27). However, there is no universal agreement regarding the timing and dosage adaptation of glucocorticoid substitution peri- and postpartum. In fact, in the vast majority of 
cases of the current evaluation, glucocorticoid in stress dosage was administered intravenously. However, a wide scatter of hydrocortisone dosage was evident during labor and individual cases reported of missing or delayed stress coverage.

A further surprising finding was the predominantly high rate of CS as delivery mode among patients with secondary Al. Because of the retrospective nature of the data retrieval, the indications for CS remain uncertain. In accordance with previous findings, the rate of CS among patients with CAH was high, for which some percentage can be assumed to be related to earlier genital surgery $(16,20,27)$. Furthermore, the increased rate of CS could also be related to the overall frequency of CS in large tertiary care hospitals (28).

Independent of the mode of delivery, most deliveries were without complications. Likewise, our study revealed good maternal and fetal outcomes for the overall patient cohort. Children born preterm were reported in all groups but were more frequent among patients with $\mathrm{CAH}$. Similarly, the mean weight and height of these children tended to be lower. In a comparable study from Germany, children born to CAH patient weighed significantly less and had a tendency to be smaller compared to the general population (16). As our study lacked information regarding the sex of the children, we were unable to report the number of children born small for gestational age. Furthermore, considering the multi-centric nature of the study with data from different countries, a clear comparison to the respective general population was not possible.

Limitations of our study include possible missing data, over- or under-reporting of some aspects of baseline or follow-up parameters, and selection bias. In particular, it should be noted that those centers that took part in the current study are specialized in the diagnosis and treatment of patients 
with $\mathrm{Al}$ and are more likely to be integrated into multidisciplinary teams as well as to provide patient management based on their clinical experience in addition to the existing guidelines. Therefore, it is possible that data gathered from expert centers will not be representative for the overall patient population. The strengths of our study include the availability of an extensive and recent dataset reflecting the current clinical management of pregnancies in women with Al from a variety of countries.

Taken together, this survey confirms good maternal and fetal outcome of pregnancies in Al treated in specialized centers. These data provide a reassuring ground for counselling of women with known Al and motivation for regular endocrine follow-up to adjust glucocorticoid and mineralocorticoid dosage during the course of pregnancy. Regarding the etiology and the prevention of miscarriages among patients with Al further prospective studies are required. 


\section{Acknowledgments}

The study has been supported by the Deutsche Forschungsgemeinschaft (DFG) within the CRC/Transregio 205/1 “The Adrenal: Central Relay in Health and Disease "to NR, SH, and FB. 
1. Bancos I, Hahner S, Tomlinson J, Arlt W. Diagnosis and management of adrenal insufficiency. Lancet Diabetes Endocrinol 2015; 3:216-226

2. Bensing S, Brandt L, Tabaroj F, Sjoberg O, Nilsson B, Ekbom A, Blomqvist P, Kampe 0. Increased death risk and altered cancer incidence pattern in patients with isolated or combined autoimmune primary adrenocortical insufficiency. Clin Endocrinol (Oxf) 2008; 69:697-704

3. Schneiderman M, Czuzoj-Shulman N, Spence AR, Abenhaim HA. Maternal and neonatal outcomes of pregnancies in women with Addison's disease: a population-based cohort study on 7.7 million births. BJOG 2017; 124:1772-1779

4. Cohen M. Addison's disease complicated by toxemia of pregnancy; review of the literature. Arch Intern Med (Chic) 1948; 81:879-887

5. Michels AW, Gottlieb PA. Autoimmune polyglandular syndromes. Nat Rev Endocrinol 2010; 6:270-277

6. Tomlinson JW, Holden N, Hills RK, Wheatley K, Clayton RN, Bates AS, Sheppard MC, Stewart PM. Association between premature mortality and hypopituitarism. West Midlands Prospective Hypopituitary Study Group. Lancet 2001; 357:425431

7. Vila G, Fleseriu M. Fertility and Pregnancy in Women With Hypopituitarism: A Systematic Literature Review. J Clin Endocrinol Metab 2020; 105

8. Bjornsdottir S, Cnattingius S, Brandt L, Nordenstrom A, Ekbom A, Kampe O, Bensing S. Addison's disease in women is a risk factor for an adverse pregnancy outcome. The Journal of clinical endocrinology and metabolism 2010; 95:52495257

9. Duthie L, Reynolds RM. Changes in the maternal hypothalamic-pituitary-adrenal axis in pregnancy and postpartum: influences on maternal and fetal outcomes. Neuroendocrinology 2013; 98:106-115

10. Hahner S, Spinnler C, Fassnacht M, Burger-Stritt S, Lang K, Milovanovic D, Beuschlein F, Willenberg HS, Quinkler M, Allolio B. High incidence of adrenal crisis in educated patients with chronic adrenal insufficiency: a prospective study. The Journal of clinical endocrinology and metabolism 2015; 100:407-416

11. Bornstein SR, Allolio B, Arlt W, Barthel A, Don-Wauchope A, Hammer GD, Husebye ES, Merke DP, Murad MH, Stratakis CA, Torpy DJ. Diagnosis and Treatment of Primary Adrenal Insufficiency: An Endocrine Society Clinical Practice Guideline. J Clin Endocrinol Metab 2016; 101:364-389

12. Jung C, Ho JT, Torpy DJ, Rogers A, Doogue M, Lewis JG, Czajko RJ, Inder WJ. A Longitudinal Study of Plasma and Urinary Cortisol in Pregnancy and Postpartum. J Clin Endocr Metab 2011; 96:1533-1540

13. Punthakee Z, Legault L, Polychronakos C. Prednisolone in the treatment of adrenal insufficiency: a re-evaluation of relative potency. J Pediatr 2003; 143:402-405

14. Quinkler M, Oelkers W, Remde H, Allolio B. Mineralocorticoid substitution and monitoring in primary adrenal insufficiency. Best Pract Res Clin Endocrinol Metab 2015; 29:17-24

15. Oksnes M, Bjornsdottir S, Isaksson M, Methlie P, Carlsen S, Nilsen RM, Broman JE, Triebner K, Kampe 0, Hulting AL, Bensing S, Husebye ES, Lovas K. Continuous Subcutaneous Hydrocortisone Infusion versus Oral Hydrocortisone Replacement 
for Treatment of Addison's Disease: A Randomized Clinical Trial. J Clin Endocr Metab 2014; 99:1665-1674

16. Remde H, Zopf K, Schwander J, Quinkler M. Fertility and Pregnancy in Primary Adrenal Insufficiency in Germany. Horm Metab Res 2016; 48:306-311

17. Hagenfeldt K, Janson PO, Holmdahl G, Falhammar H, Filipsson H, Frisen L, Thoren $\mathrm{M}$, Nordenskjold A. Fertility and pregnancy outcome in women with congenital adrenal hyperplasia due to 21-hydroxylase deficiency. Hum Reprod 2008; 23:1607-1613

18. Avalos LA, Galindo C, Li DK. A Systematic Review to Calculate Background Miscarriage Rates using Life Table Analysis. Birth Defects Res A 2012; 94:417423

19. Wilcox AJ, Weinberg CR, Oconnor JF, Baird DD, Schlatterer JP, Canfield RE, Armstrong EG, Nisula BC. Incidence of Early Loss of Pregnancy. New Engl J Med 1988; 319:189-194

20. Krone N, Wachter I, Stefanidou M, Roscher AA, Schwarz HP. Mothers with congenital adrenal hyperplasia and their children: outcome of pregnancy, birth and childhood. Clin Endocrinol (Oxf) 2001; 55:523-529

21. Quinkler M, Meyer B, Bumke-Vogt C, Grossmann C, Gruber U, Oelkers W, Diederich S, Bahr V. Agonistic and antagonistic properties of progesterone metabolites at the human mineralocorticoid receptor. European journal of endocrinology / European Federation of Endocrine Societies 2002; 146:789-799

22. Quinkler M, Meyer B, Oelkers W, Diederich S. Renal inactivation, mineralocorticoid generation, and 11beta-hydroxysteroid dehydrogenase inhibition ameliorate the antimineralocorticoid effect of progesterone in vivo. J Clin Endocrinol Metab 2003; 88:3767-3772

23. Reisch N. Pregnancy in Congenital Adrenal Hyperplasia. Endocrinol Metab Clin North Am 2019; 48:619-641

24. Oelkers WK. Effects of estrogens and progestogens on the renin-aldosterone system and blood pressure. Steroids 1996; 61:166-171

25. Hadlow N, Sikaris K. Aspects to Consider in Adopting Pregnancy-Specific Reference Intervals. Clin Biochem Rev 2015; 36:127-132

26. Reisch N, Willige M, Kohn D, Schwarz HP, Allolio B, Reincke M, Quinkler M, Hahner S, Beuschlein F. Frequency and causes of adrenal crises over lifetime in patients with 21-hydroxylase deficiency. European Journal of Endocrinology 2012; 167:35-42

27. Lebbe $M$, Arlt $W$. What is the best diagnostic and therapeutic management strategy for an Addison patient during pregnancy? Clin Endocrinol (Oxf) 2013; 78:497-502

28. Betran AP, Ye J, Moller AB, Zhang J, Gulmezoglu AM, Torloni MR. The Increasing Trend in Caesarean Section Rates: Global, Regional and National Estimates: 1990-2014. PLoS One 2016; 11:e0148343 
Tables

Table 1: Baseline characteristics of pregnant patients with adrenal insufficiency.

\begin{tabular}{|c|c|c|c|c|c|}
\hline & $\begin{array}{c}A D \\
(n=56)\end{array}$ & $\begin{array}{l}\text { Secondary AI } \\
\qquad(n=32)\end{array}$ & $\begin{array}{l}\mathrm{CAH} \\
(n=32)\end{array}$ & $\begin{array}{c}\text { Other } \\
\text { reason for Al }\end{array}$ & P-value \\
\hline $\begin{array}{l}\text { Age at } \\
\text { diagnosis } \\
\text { (years) }\end{array}$ & $26[14,35]$ & $26[8,44]$ & $9[0,38]$ & $30[23,37]$ & $<0.001^{\mathrm{a}}$ \\
\hline $\begin{array}{l}\text { Age at } \\
\text { pregnancy } \\
\text { (years) }\end{array}$ & $32.7 \pm 4.5$ & $32.0 \pm 5.5$ & & $34.9 \pm 3.8$ & $0.470^{b}$ \\
\hline $\begin{array}{l}\text { Baseline BMI } \\
\left(\mathrm{kg} / \mathrm{m}^{2}\right)\end{array}$ & $24.3 \pm 4.5$ & $27.5 \pm 6.9$ & $25.7 \pm 4.6$ & $24.3 \pm 6.0$ & $0.143^{a}$ \\
\hline
\end{tabular}

AD, Addison Disease; Al, adrenal insufficiency; $\mathrm{CAH}$, congenital adrenal hyperplasia; BMI, Body Mass Index; Values are given as median [range] or mean $\pm S D ;{ }^{a}$ Kruskal- Wallis test, ${ }^{b}$ One-way ANOVA 
Table 2: Hydrocortisone equivalent dosage and total mineralocorticoid factor before pregnancy and per trimester divided in different subgroups of patients with adrenal insufficiency.

\begin{tabular}{|c|c|c|c|c|c|}
\hline & AD & Secondary Al & CAH & $\begin{array}{c}\text { Other } \\
\text { reasons of Al }\end{array}$ & P-value ${ }^{a}$ \\
\hline \multicolumn{6}{|c|}{ Before pregnancy } \\
\hline $\begin{array}{c}\text { Daily HC } \\
\text { equivalent } \\
\text { dosage }(\mathrm{mg})\end{array}$ & $\begin{array}{c}22.4[15.0- \\
31.4] \\
n=39\end{array}$ & $\begin{array}{c}18.1[7.5- \\
40.0] \\
n=25\end{array}$ & $\begin{array}{c}21.8[6.3- \\
50.0] \\
n=31\end{array}$ & $\begin{array}{c}18.5[15-20] \\
n=5\end{array}$ & 0.012 \\
\hline Total MCU & $\begin{array}{c}2.0[0.8-3.4] \\
n=39\end{array}$ & $\begin{array}{c}0.9[0.0-2.2] \\
n=26\end{array}$ & $\begin{array}{c}1.5[0.1-4.2] \\
n=29\end{array}$ & $\begin{array}{c}1.9[1.1-2.5] \\
n=5\end{array}$ & $<0.001$ \\
\hline \multicolumn{6}{|c|}{$\mathbf{1}^{\text {st }}$ trimester } \\
\hline $\begin{array}{c}\text { Daily HC } \\
\text { equivalent } \\
\text { dosage (mg) }\end{array}$ & $\begin{array}{c}24.0[15-40] \\
n=53\end{array}$ & $\begin{array}{c}18.8[7.5-40] \\
n=25\end{array}$ & $\begin{array}{c}21.8[7.5-45] \\
n=30\end{array}$ & $\begin{array}{c}23.8[20-30] \\
n=8\end{array}$ & 0.02 \\
\hline Total MCU & $\begin{array}{c}2.1[0.0-4.2] \\
n=56\end{array}$ & $\begin{array}{c}0.7[0.0-2.2] \\
n=32\end{array}$ & $\begin{array}{c}1.3[0.0-4.2] \\
n=31\end{array}$ & $\begin{array}{c}2.3[1.4-3.1] \\
n=8\end{array}$ & $<0.001$ \\
\hline \multicolumn{6}{|c|}{$2^{\text {nd }}$ trimester } \\
\hline $\begin{array}{c}\text { Daily HC } \\
\text { equivalent } \\
\text { dosage (mg) }\end{array}$ & $\begin{array}{c}27.4[15-70] \\
n=50\end{array}$ & $\begin{array}{c}21.6[10-60] \\
n=28\end{array}$ & $\begin{array}{c}23.9[7.5-45] \\
n=30\end{array}$ & $\begin{array}{c}25[20-30] \\
n=7\end{array}$ & 0.24 \\
\hline Total MCU & $\begin{array}{c}2.4[0.9-5.8] \\
n=51\end{array}$ & $\begin{array}{c}1.0[0.5-2.2] \\
n=28\end{array}$ & $\begin{array}{c}1.4[0.1-4.2] \\
n=29\end{array}$ & $\begin{array}{c}2.6[1.4-4.6] \\
n=7\end{array}$ & $<0.001$ \\
\hline \multicolumn{6}{|c|}{$3^{\text {rd }}$ trimester } \\
\hline $\begin{array}{c}\text { Daily HC } \\
\text { equivalent } \\
\text { dosage (mg) }\end{array}$ & $\begin{array}{c}26.6[10-40] \\
n=50\end{array}$ & $\begin{array}{c}23.0[10-50] \\
n=27\end{array}$ & $\begin{array}{c}25.6[7.5-50] \\
n=28\end{array}$ & $\begin{array}{c}25.7[20-35] \\
n=7\end{array}$ & 0.053 \\
\hline
\end{tabular}




\begin{tabular}{|l|c|c|c|c|c|}
\hline Total MCU & $2.4[0.9-4.1]$ & $1.1[0.5-2.2]$ & $1.8[0.1-5.6]$ & $2.7[1.4-4.4]$ & $<0.001$ \\
& $\mathrm{n}=50$ & $\mathrm{n}=27$ & $\mathrm{n}=26$ & $\mathrm{n}=7$ & \\
\hline
\end{tabular}

$A D$, Addison Disease; $\mathrm{Al}$, adrenal insufficiency; $\mathrm{CAH}$, congenital adrenal hyperplasia; $\mathrm{HC}$, hydrocortisone; $\mathrm{MCU}$, mineralocorticoid unit; Values are given as median [range] or mean $\pm \mathrm{SD}$

${ }^{a}$ Kruskal- Wallis test 
Table 3: Development of blood pressure and serum electrolytes during pregnancy in patients with adrenal insufficiency.

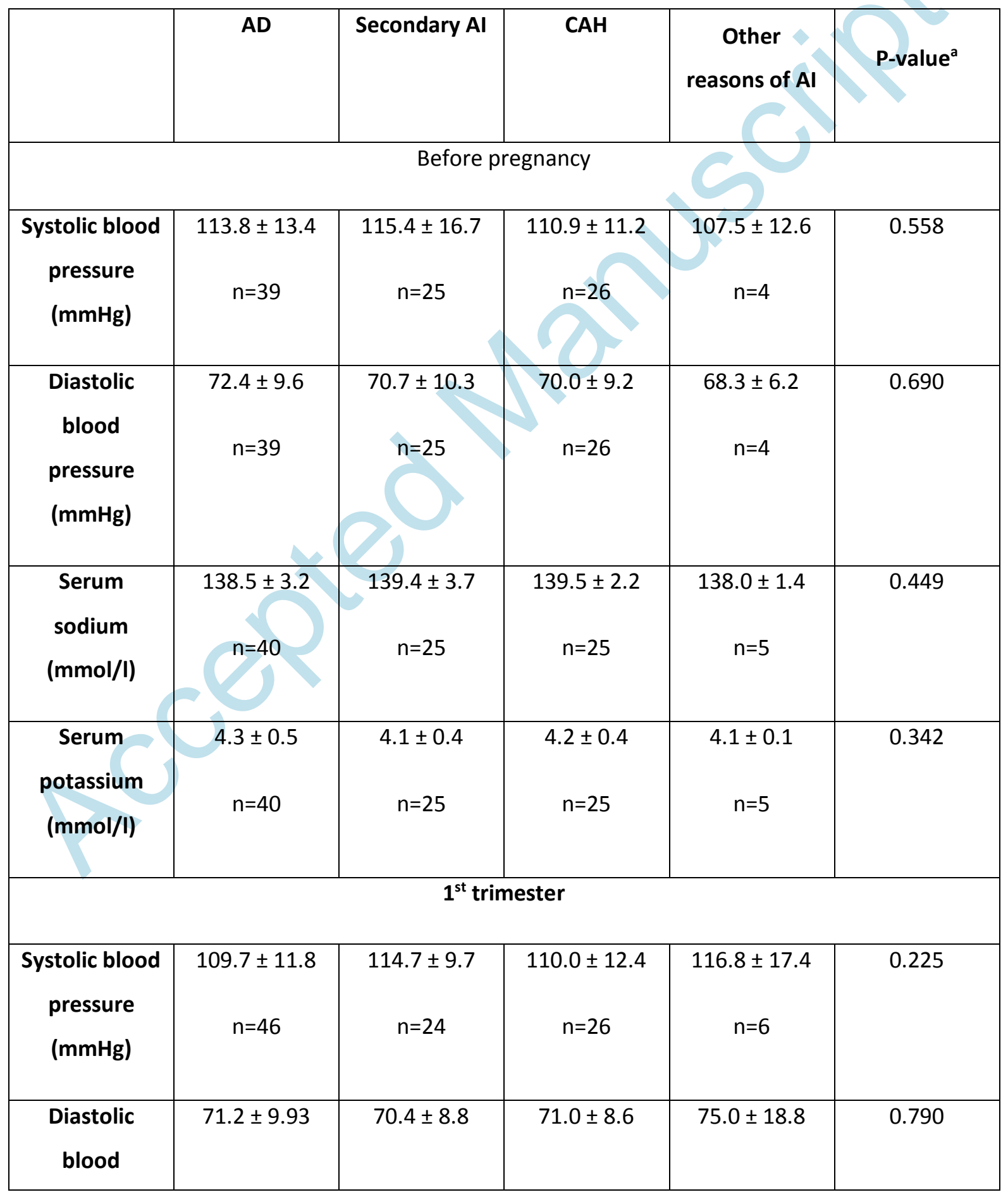




\begin{tabular}{|c|c|c|c|c|c|}
\hline $\begin{array}{l}\text { pressure } \\
(\mathrm{mmHg})\end{array}$ & $n=46$ & $n=24$ & $n=26$ & $\mathrm{n}=6$ & \\
\hline $\begin{array}{l}\text { Serum } \\
\text { sodium } \\
\text { (mmol/l) }\end{array}$ & $\begin{array}{c}135.2 \pm 2.1 \\
n=44\end{array}$ & $\begin{array}{c}137.5 \pm 2.9 \\
n=15\end{array}$ & $\begin{array}{c}137.6 \pm 2.6 \\
n=23\end{array}$ & $\begin{array}{c}136.1 \pm 2.7 \\
n=7\end{array}$ & $<0.001$ \\
\hline $\begin{array}{c}\text { Serum } \\
\text { potassium } \\
\text { (mmol/l) }\end{array}$ & $\begin{array}{c}4.2 \pm 0.3 \\
n=43\end{array}$ & $\begin{array}{c}4.1 \pm 0.5 \\
n=15\end{array}$ & $\begin{array}{c}4.0 \pm 0.4 \\
n=23\end{array}$ & $\begin{array}{c}4.3 \pm 0.2 \\
n=7\end{array}$ & 0.076 \\
\hline \multicolumn{6}{|c|}{$2^{\text {nd }}$ trimester } \\
\hline $\begin{array}{c}\text { Systolic blood } \\
\text { pressure } \\
(\mathrm{mmHg})\end{array}$ & $\begin{array}{c}108.4 \pm 11.1 \\
n=45\end{array}$ & $\begin{array}{c}114.9 \pm 15.3 \\
n=23\end{array}$ & $111.1 \pm 9.4$ & $\begin{array}{c}120.6 \pm 12.9 \\
n=7\end{array}$ & 0.034 \\
\hline $\begin{array}{c}\text { Diastolic } \\
\text { blood } \\
\text { pressure } \\
\text { (mmHg) }\end{array}$ & $\begin{array}{c}66.0 \pm 8.3 \\
n=45\end{array}$ & $71.9 \pm 8.1$ & $\begin{array}{c}69.1 \pm 7.7 \\
n=27\end{array}$ & $\begin{array}{c}78.2 \pm 10.4 \\
n=7\end{array}$ & 0.001 \\
\hline $\begin{array}{l}\text { Serum } \\
\text { sodium } \\
\text { (mmol/l) }\end{array}$ & $135.9 \pm 2.7$ & $\begin{array}{c}138.1 \pm 2.5 \\
n=18\end{array}$ & $\begin{array}{c}136.3 \pm 3.9 \\
n=24\end{array}$ & $\begin{array}{c}136.7 \pm 2.8 \\
n=6\end{array}$ & 0.052 \\
\hline $\begin{array}{c}\text { Serum } \\
\text { potassium } \\
\text { (mmol/l) }\end{array}$ & $\begin{array}{l}4.1 \pm 0.4 \\
n=40\end{array}$ & $\begin{array}{c}3.9 \pm 0.5 \\
n=25\end{array}$ & $\begin{array}{c}4.0 \pm 0.3 \\
n=25\end{array}$ & $\begin{array}{c}4.1 \pm 0.4 \\
n=5\end{array}$ & 0.415 \\
\hline \multicolumn{6}{|c|}{$3^{\text {rd }}$ trimester } \\
\hline $\begin{array}{l}\text { Systolic blood } \\
\text { pressure } \\
(\mathrm{mmHg})\end{array}$ & $\begin{array}{c}111.4 \pm 12.3 \\
n=43\end{array}$ & $\begin{array}{c}117.0 \pm 16.7 \\
n=25\end{array}$ & $\begin{array}{c}118.7 \pm 16.4 \\
n=25\end{array}$ & $\begin{array}{c}112.4 \pm 12.0 \\
n=7\end{array}$ & 0.487 \\
\hline $\begin{array}{c}\text { Diastolic } \\
\text { blood } \\
\text { pressure }\end{array}$ & $\begin{array}{c}74.1 \pm 11.9 \\
n=43\end{array}$ & $\begin{array}{c}75.7 \pm 14.1 \\
n=25\end{array}$ & $\begin{array}{c}70.2 \pm 8.6 \\
n=25\end{array}$ & $\begin{array}{c}71.7 \pm 6.2 \\
n=7\end{array}$ & 0.359 \\
\hline
\end{tabular}




\begin{tabular}{|c|c|c|c|c|c|}
\hline $\begin{array}{c}\text { (mmHg) } \\
\begin{array}{c}\text { Serum } \\
\text { (mmodium }\end{array}\end{array}$ & $137.2 \pm 2.9$ & $138.6 \pm 2.5$ & $137.7 \pm 2.7$ & $137.8 \pm 3.1$ & 0.376 \\
\hline $\begin{array}{c}\text { Serum } \\
\text { potassium } \\
\text { (mmol/l) }\end{array}$ & $4.1 \pm 0.4$ & $4.0 \pm 0.4$ & $4.0 \pm 0.4$ & $4.1 \pm 0.3$ & 0.653 \\
\hline
\end{tabular}

AD, Addison Disease; Al, adrenal insufficiency; CAH, congenital adrenal hyperplasia; BMI, Body Mass Index; Values are given as median [range] or mean $\pm S D$; ${ }^{a}$ ANOVA 
Table 4: Course and outcome of pregnancies in patients with adrenal insufficiency.

\begin{tabular}{|c|c|c|c|c|c|}
\hline & $\begin{array}{c}A D \\
(n=56)\end{array}$ & $\begin{array}{l}\text { Secondary Al } \\
\qquad(n=32)\end{array}$ & $\begin{array}{l}\text { CAH } \\
(n=32)\end{array}$ & $\begin{array}{l}\text { Other reason } \\
\text { for Al } \\
(n=8)\end{array}$ & P-value \\
\hline $\begin{array}{l}\text { Spontaneous } \\
\text { abortions (\%) }\end{array}$ & $15 / 55(27.3)$ & $5 / 32(15.6)$ & $14 / 32(43.8)$ & $2 / 8(25.0)$ & $<0.001^{a}$ \\
\hline $\begin{array}{l}\text { Adrenal crisis } \\
\text { during } \\
\text { pregnancy } \\
\text { (\%) }\end{array}$ & $5 / 56(8.9)$ & $2 / 32(6.3)$ & $2 / 32(6.3)$ & & $0.607^{a}$ \\
\hline $\begin{array}{l}\text { Caesarean } \\
\text { section (\%) }\end{array}$ & $24 / 50(48.0)$ & $20 / 29(69.0)$ & $20 / 31(64.5)$ & $5 / 8(62.5)$ & $0.224^{a}$ \\
\hline Week of labor & $37.9 \pm 2.2$ & $38.7 \pm 1.8$ & $37.0 \pm 3.3$ & $37.5 \pm 2.2$ & $0.075^{b}$ \\
\hline $\begin{array}{l}\text { Preterm } \\
\text { births (\%) }\end{array}$ & $8 / 50(16.0)$ & $6 / 28(21.4)$ & $10 / 31(32.3)$ & $1 / 8(12.5)$ & $0.335^{\mathrm{a}}$ \\
\hline $\begin{array}{l}\text { First APGAR } \\
\text { score }\end{array}$ & $8.3 \pm 1.5$ & $8.6 \pm 1.8$ & $8.7 \pm 0.8$ & $8.3 \pm 1.0$ & $0.739^{b}$ \\
\hline $\begin{array}{l}\text { Child height } \\
\text { (cm) }\end{array}$ & $48.7 \pm 3.3$ & $51.0 \pm 5.1$ & $48.1 \pm 4.7$ & $51.5 \pm 0.7$ & $0.337^{b}$ \\
\hline $\begin{array}{l}\text { Child weight } \\
\text { (g) }\end{array}$ & $3261 \pm 606$ & $3322 \pm 674$ & $2934 \pm 696$ & $2814 \pm 344$ & $0.063^{b}$ \\
\hline
\end{tabular}

AD, Addison Disease; Al, adrenal insufficiency; $C A H$, congenital adrenal hyperplasia; Values are given as median [range] or mean $\pm S D ;{ }^{a}$ Kruskal- Wallis test, ${ }^{b}$ One-way ANOVA 


\section{Figure legends}

Figure 1: Dosage adaptation for daily glucocorticoid (upper panel) and mineralocorticoid (middle panel) substitution therapy and calculated total mineralocorticoid potency (lower panel) during pregnancy for women with adrenal insufficiency. TM, trimester; HC, hydrocortisone. Stars denote significant differences in comparison to baseline $(*=p<0.05 ; * *=p<0.01 ; * * *=p<0.001)$.

Figure 2: Systolic and diastolic blood pressure (upper panel) and serum electrolytes with sodium (middle panel) and potassium (lower panel) during pregnancy for women with adrenal insufficiency. $\mathrm{TM}$, trimester. Stars denote significant differences in comparison to baseline $\left(^{*}=p<0.05 ;{ }^{* *}=p<0.01\right.$; $* * *=p<0.001)$.

Figure 3: Relation between mineralocorticoid potency and serum electrolytes at baseline and during the three trimesters of pregnancy. AD, Addison disease; Al, Adrenal Insufficiency, CAH; Congenital Adrenal Hyperplasia. 
Figure 1

$\square$ increase $\square$ no adaptation $\square$ decrease
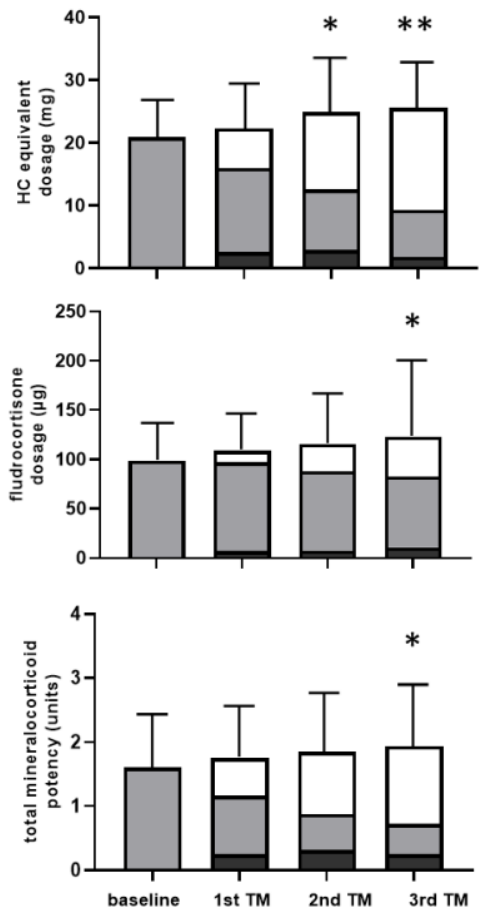
Figure 2

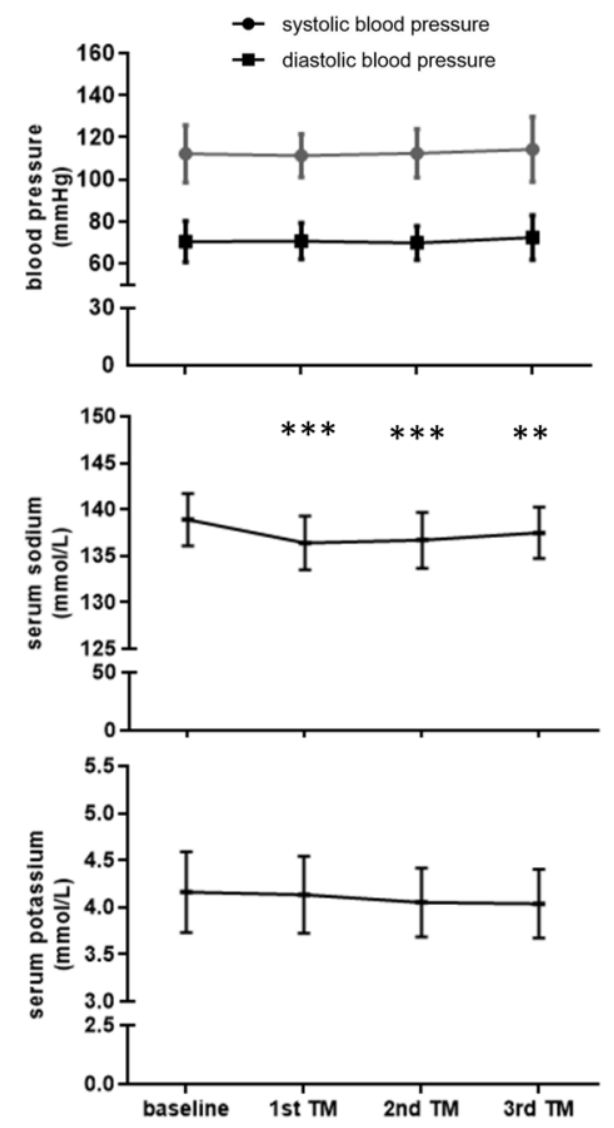


Figure 3

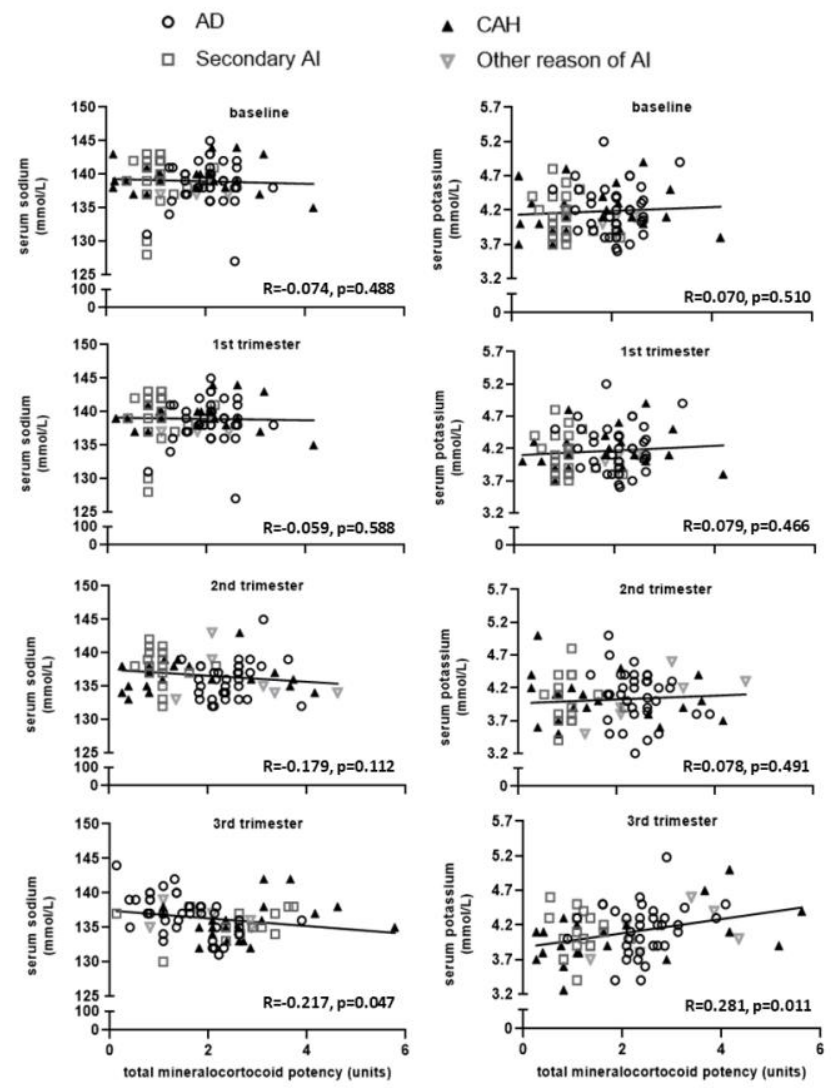

